\title{
DIFFERENTIAL AMPHIPLASTY AND THE CONTROL OF RIBOSOMAL RNA SYNTHESIS*
}

\author{
H. WALLACE \\ Department of Genetics, University of Birmingham, England \\ and \\ W. H. R. LANGRIDGE \\ Department of Biology, Amherst College, Amherst, Mass., U.S.A.
}

Received 1.ix.70

\section{INTRODUGTION}

\begin{abstract}
"That the ability of the nucleolar organizer to form nucleoli is under genetic control has also been demonstrated in hybrids of the plant genus Crepis. Each species of Crepis has its distinctive nucleolar organizer, but when brought into a common nucleus through hybridization, the organizers exhibit differential synthetic ability in the hybrid environment; only one of them will form a nucleolus, the other remaining inactive. When inactive, no nucleolus forms and the secondary constriction will be missing from the metaphase chromosomes. A number of Crepis species, therefore, can be graded on the competitive strength of their nucleolar organizers. An inactive organizer, on the other hand, regains its synthetic ability when placed back in a more favourable nuclear situation, and the metaphase chromosome will again show a secondary constriction."
\end{abstract}

SWANSON, MERZ AND YOUNG, 1967, p. 29

This quotation asserts the conclusion that we intend to demonstrate in the following article. The initial sentence of the quotation may be taken as a logical premise that requires substantiation. The premise is based partly on the description of differential amphiplasty in Crepis hybrids by Navashin (1934), where the secondary constriction of one chromosome was seen to be missing, and partly on McClintock's (1934) celebrated description of the nucleolar organiser in maize.

\section{(i) Differential amphiplasty}

On the chromosome nomenclature formulated by Navashin (1925), and generally used for Crepis, the D chromosomes are identified at mitotic divisions by a secondary constriction which separates a satellite (or trabant) from the rest of the short arm. The constriction and satellite are constant features of both $\mathrm{D}$ chromosomes in diploids, both of pure species and some interspecific hybrids. Other hybrids, however, consistently show a constriction and satellite on only one D chromosome; the other species D chromosome has " retracted its satellite", thus showing no secondary constriction. No secondary constriction is present, for instance, on the neglecta D chromosome in C. capillaris-C. neglecta hybrids (fig. 1). Navashin showed that the neglecta $\mathrm{D}$ chromosome was invariably affected in this way in hybrids from reciprocal crosses of the two species, and thus excluded any maternal or cytoplasmic effect. Back-crossing such hybrids to $C$. neglecta apparently yielded two kinds of viable offspring: pure neglecta which showed secondary

* This study was initially supported by U.S. Public Health Service Grant GM 14166. 
constrictions on both $\mathrm{D}$ chromosomes; and further hybrids containing the complete set of capillaris chromosomes and either one or two sets of neglecta chromosomes lacking any secondary constrictions. Navashin (1934) concluded that differential amphiplasty was a reversible effect resulting from the interaction of alien chromosomes. Either the whole capillaris set, or part of that set, of chromosomes prevents the formation of a secondary constriction on the neglecta $\mathrm{D}$ chromosome. This interaction is not affected by dosage.
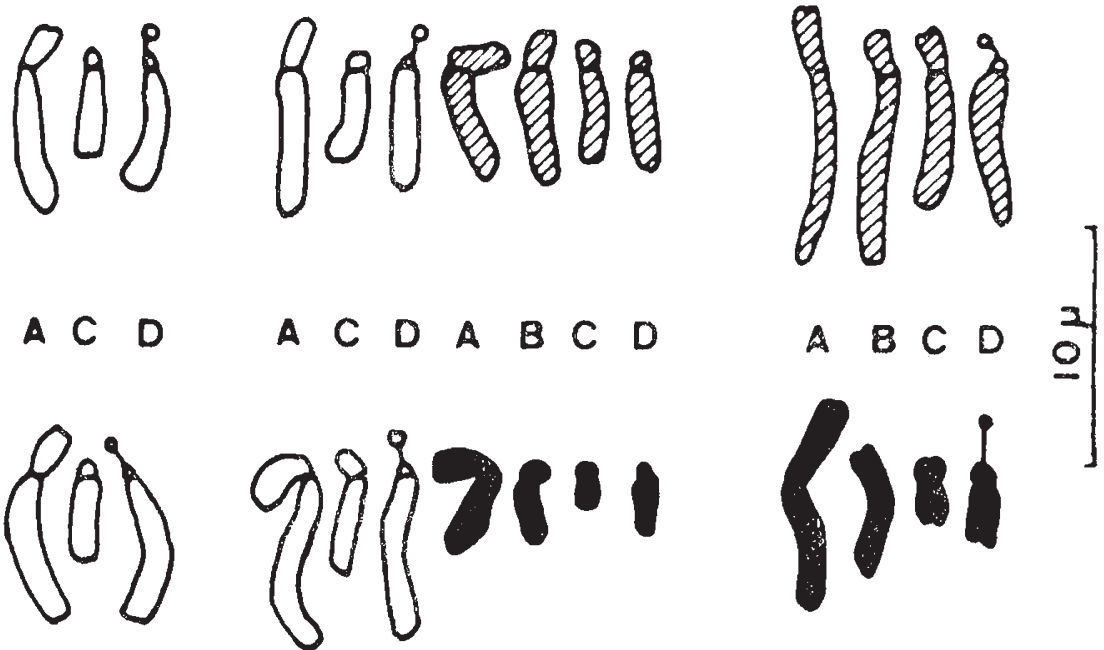

Fig. 1.-Chromosomes traced from photographs of mitotic metaphase in root-tips of $C$. capillaris (outline), C. tectorum (hatched) and C. neglecta (black). Top row: capillaris $(\mathrm{N}=3)$, capillaris-tectorum hybrid, tectorum $(\mathrm{N}=4)$. Bottom row: capillaris, capillarisneglecta hybrid, neglecta $(\mathrm{N}=4)$. Note that the tectorum $\mathrm{D}$ and neglecta $\mathrm{D}$ chromosomes do not show secondary constrictions and satellites in the hybrids. The excessive contraction of all tectorum and neglecta chromosomes in the hybrids (neutral amphiplasty) is an independent phenomenon (see Navashin, 1934; Langridge, O'Malley and Wallace, 1970).

Although Navashin was well aware that nucleoli are associated with secondary constrictions, he did not record any nucleolar changes in these hybrids. Such changes would be difficult to detect in his sections of roottips, where the majority of interphase nuclei show only a single nucleolus. The meiotic divisions offer more scope for observing nucleoli (cf. Richardson, 1935). Meiosis is very abnormal in Crepis hybrids, however, and has been recorded in sufficient detail only for two hybrids, capillaris-aspera (Navashin, 1927) and fuliginosa-neglecta (Tobgy, 1943), neither of which exhibit differential amphiplasty.

\section{(ii) nucleolar organiser}

McClintock (1934) coined the term nucleolar organiser to account for the effect of translocations on the formation of nucleoli in Zea mays. McClintock's two principal conclusions were $(a)$ the nucleolar organiser functions as a site of collection of material from other chromosomal loci; and $(b)$ the locus of the nucleolar organiser is not the secondary constriction, but a large pachytene chromomere adjacent to it. These conclusions have been 
widely accepted for over 30 years (cf. Wallace, 1962), but the first is now greatly modified in emphasis (Birnstiel, 1967) and we repudiate the second in this article. McClintock's observations also supported the general assumption that the absence of a secondary constriction (at mitosis or meiotic prophase) implied the failure to form a nucleolus at that site during the preceding telophase and interphase. On that basis, McClintock (1934, p. 326) offered a theoretical interpretation of differential amphiplasty in terms of competition between organisers to collect " matrix " into a nucleolus. In our example of capillaris-neglecta hybrids, McClintock predicted that the neglecta organiser would not produce a nucleolus (or only a very small one), but that prediction has not previously been verified for any Crepis hybrids. Noting the consistent occurrence of differential amphiplasty, McClintock (1934, p. 328) speculated that " through extended investigations, it should be possible to produce a seriated arrangement of Crepis species with regard to functional capacities of the nucleolar-organising elements of the satellited chromosomes of each species".

The results reported here confirm Navashin's (1934) conclusions on differential amphiplasty, extend them to other Crepis hybrids, and relate the presence of secondary constrictions during mitosis and meiosis to the prior formation of nucleoli. We interpret these results in terms of allelic repression between at least four isoalleles, of either the nucleolar organiser or its regulatory system, which show a heirarchy of dominance in those hybrids which have been studied.

\section{Material AND Methods}

The identification, classification and karyotypes of the species of Crepis used here are listed by Babcock (1947). We obtained seed from many of the herbaria cited by Babcock. Although we have grown and attempted to hybridise about twenty species, we have obtained only a few hybrids from a low proportion of the crosses (see table 1). Emasculation is only practicable in those species with relatively large flower heads, such as $C$. rubra. Reducing the pollen of newly opened flower heads by washing with a jet of water had little effect on self-compatible species, such as $C$. pulchra and $C$. tectorum (cf. Collins, 1922). A low yield of hybrids was obtained from relatively selfincompatible species, principally from $C$. capillaris.

C. capillaris $(2 \mathrm{~N}=6)$ plants with smooth leaves bearing spots of anthocyanin were usually used as maternal parents, allowing a selection for hybrids following pollination by rubbing flower heads together for three successive days and then enclosing the heads in bags to retain the seed. Those of their progeny which had hairy or serrated leaves were subjected to chromosome analysis. Most other Crepis species possess diploid numbers of 8, 10 or 12 chromosomes, so that the number of chromosomes is diagnostic for most hybrids, while size and shape of the chromosomes identifies other hybrids.

Several of the hybrids were propagated by means of cuttings of basal shoots, including part of the root-system wherever possible, as described by Hughes and Babcock (1950). Only one hybrid, capillaris-leontodontoides which tended to divide spontaneously, provided enough cloned material for bulk extractions. Our inability to prevent flowering and senescence was probably a major cause of loss of other hybrid clones.

Rapidly growing root-tips and isodiametric flower-buds were fixed and 
stored in ethanol-acetic acid $(3: 1)$ for temporary squash preparations. Soon after fixation, material was hydrolysed in $1 \mathrm{~N} \mathrm{HGI}$ for 10 minutes at $60^{\circ} \mathrm{C}$. and stained with feulgen; or after prolonged storage was hydrolysed in $5 \mathrm{~N} \mathrm{HGl}$ for 15 minutes at $20^{\circ} \mathrm{C}$. and stained with aceto-orcein. These standard chromosome techniques show unstained " nuclear ghosts", and the feulgen technique often leaves secondary constrictions unstained. Nucleoli were revealed by adding ferric acetate to the fixative for several days before squashing in aceto-carmine.

\section{Results}

The eight interspecific crosses which yielded hybrids are listed in table 1 , to summarise our observations on somatic tissues. Several (3-8) hybrid seedlings were obtained from each of these crosses and all, except capillaristectorum, grew vigorously enough to be propagated from cuttings. The

TABLE 1

Nuclear characteristics of Crepis hybrids. (From root-tips, compare figs. 1 and 2)

\begin{tabular}{|c|c|c|c|c|}
\hline$\overbrace{}^{\text {Parent species }}$ & Number of & Satellite retracted on & $\begin{array}{l}\text { Number of } \\
\text { secondary }\end{array}$ & $\begin{array}{l}\text { Maximum } \\
\text { number of }\end{array}$ \\
\hline Maternal Paternal & chromosomes & D chromosome of: & constrictions & nucleoli \\
\hline capillaris-aspera & 7 & - & 2 & 2 \\
\hline capillaris-tectorum & 7 & tectorum & 1 & 1 \\
\hline capillaris-leontodontoides & 8 & leontodontoides & 1 & 1 \\
\hline capillaris-rubra & $6-8$ & rubra & 1 & 1 \\
\hline capillaris-nicaeensis & 7 & nicaeensis & 1 & 1 \\
\hline capillaris-neglecta & 7 & neglecta & 1 & 1 \\
\hline neglecta-capillaris & 7 & neglecta & 1 & 1 \\
\hline aspera-fuliginosa & 7 & fuliginosa & 1 & 1 \\
\hline
\end{tabular}

nuclear characters shown in table 1 were maintained in the clones produced in this way. All the hybrids started with a complete set of maternal and paternal chromosomes and all, except capillaris-rubra, maintained this stable karyotype. The six capillaris-rubra seedlings each lost one or two rubra chromosomes in different sectors of their root-systems, but tended to stabilise at the karyotype shown in fig. 2. Such losses of specific chromosomes, which are currently being exploited in somatic cell-hybrids (e.g. Klebe, Chen and Ruddle, 1970), may be explicable in terms of specific differences in the mitotic cycle (Langridge, O’Malley and Wallace, 1970).

\section{(i) Secondary constrictions during mitosis}

Five of the hybrids listed in table 1 duplicate previous reports, and add support to Navashin's (1934) analysis, of differential amphiplasty. In particular, we confirm that the neglecta $\mathrm{D}$ chromosome shows no secondary constriction in capillaris-neglecta hybrids produced by reciprocal crosses. The three novel hybrids shown in table 1, capillaris-rubra, capillaris-nicaeensis and aspera-fuliginosa, all exhibit differential amphiplasty in the manner predicted by McClintock (1934). The formal argument for this prediction is explained below.

The recorded instances of differential amphiplasty in Crepis hybrids can be set out to show a heirarchy of dominance, characteristic of any series of multiple alleles, under the following assumptions. The secondary con- 
striction and satellite are considered as the expression of a single locus, $S$, potentially occupied by a different allele in each species (A, B, etc.). Such alleles $\left(S^{a}, S^{b}\right)$ are then either identical or co-dominant in the hybrid $\mathrm{AB}$ if no differential amphiplasty occurs $\left(S^{a}=S^{b}\right) ; S^{a}$ is dominant to $S^{b}\left(S^{a} \rightarrow S^{b}\right)$, however, if differential amphiplasty is recognised by the retraction of the species B satellite. The heirarchy shown in fig. 3 then satisfies the formal rules of dominance, identifying each allele by the suffix only:

$$
\begin{aligned}
& \text { if } a=b \text { and } b=c \text {, then } a=c \text {; } \\
& \text { if } b=c \text { and } c \rightarrow d \text {, then } b \rightarrow d ; \\
& \text { if } c \rightarrow d \text { and } d=e \text {, then } c \rightarrow e ; \\
& \text { if } c \rightarrow d \text { and } d \rightarrow f \text {, then } c \rightarrow f \text {. }
\end{aligned}
$$

a)

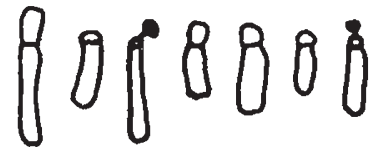

A C D A B C D

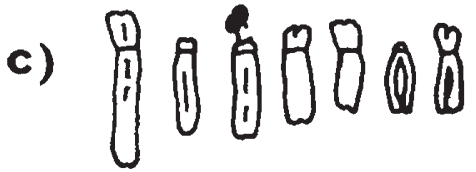

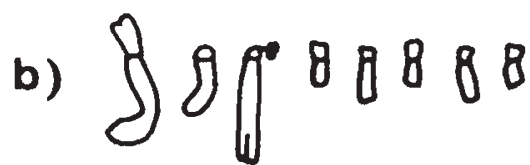

A C D A B C D E

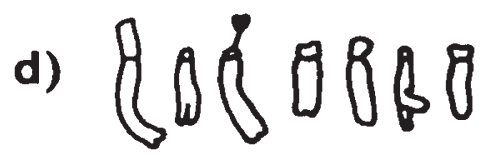

FIG. 2.-Chromosomes traced from photographs of mitotic metaphase in root-tips of hybrids: (a) capillaris-aspera, (b) capillaris-leontodontoides, (c) capillaris-nicaeensis, (d) capillaris-rubra. The three capillaris chromosomes are shown on the left of each idiogram. Note that secondary constrictions and satellites (black) are present only on capillaris D and aspera D chromosomes. The rubra $\mathrm{E}$ chromosome is missing.

An example of this sequence can be followed in fig. 3 , if $a-f$ represent the alleles of the species aspera, setosa, capillaris, tectorum, neglecta and leontodontoides, respectively. This interpretation has an internal consistency in that a species is dominant for this character to any other species placed lower in fig. 3. The predictive value of the interpretation has already been tested, as McClintock (1934) first recognised the heirarchy on the basis of 21 hybrids and the 9 hybrids recorded since then conform to the same pattern. There are at least four alleles in the series, shown by the four ranks of dominance in the heirarchy.

\section{(ii) Nucleoli in root-tips}

The hybrids shown in table 1 demonstrate a perfect correspondence between the number of secondary constrictions and the maximum number of nucleoli found in cells of the same root-tips. Although the majority of cells in the parent species contain only one nucleolus, this is presumably a fusion product (cf. Wallace, 1963) for a minor proportion of the cells possess two distinct nucleoli. The capillaris-aspera hybrid resembles both parent species in forming two nucleoli in some cells and regularly showing secondary constrictions and satellites on both $\mathrm{D}$ chromosomes (fig. 2). The seven hybrids showing differential amphiplasty, however, have uniformly revealed only one nucleolus in each diploid nucleus of their root-tips. The nucleolus 
disappears in mitotic prophase, before we can reliably identify the chromosome to which it was attached. We suppose that the nucleolus was formed on the only secondary constriction present in these hybrids, but we cannot demonstrate the point in somatic tissues.

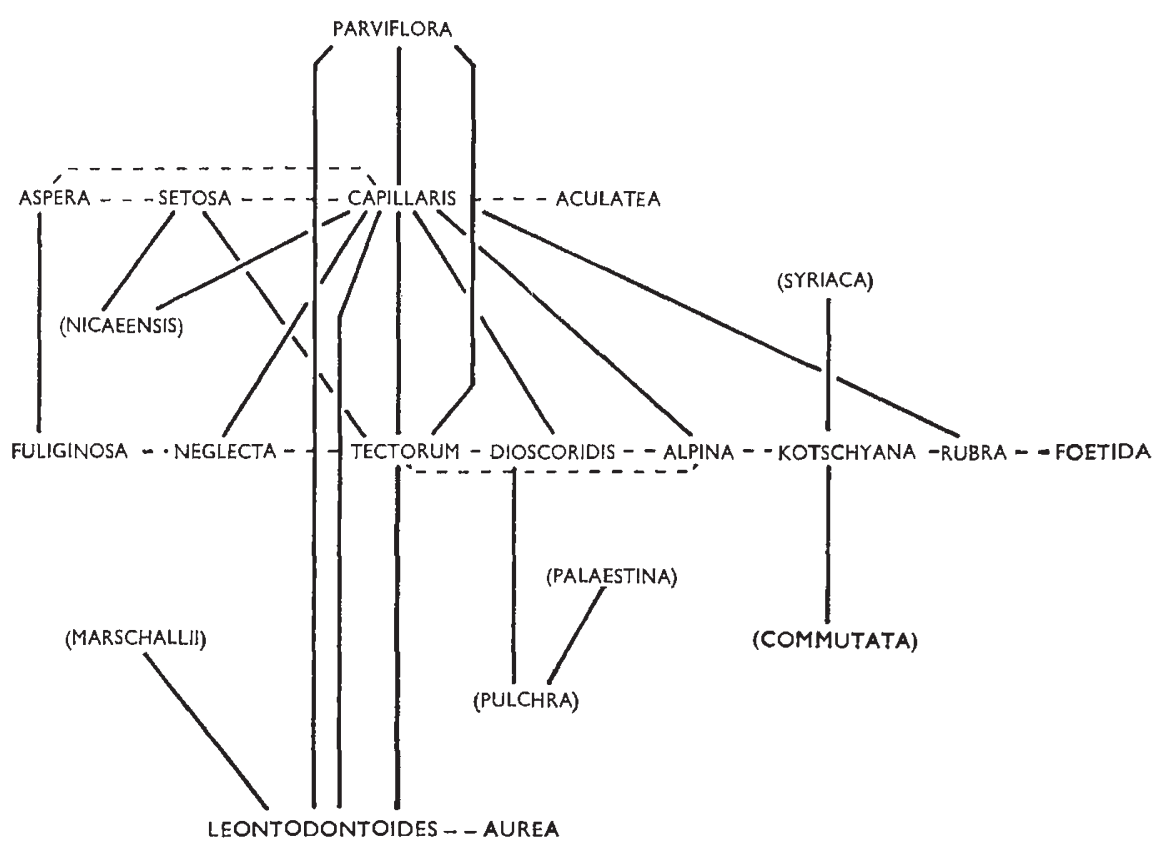

FIG. 3.-Heirarchy of dominance in cases of differential amphiplasty. Known cases of differential amphiplasty among Crepis hybrids are recorded as solid lines connecting the names of their parent species. In such hybrids, the satellite of the lower (recessive) parent is retracted. No differential amphiplasty occurs in hybrids shown by broken lines connecting (co-dominant) parents on the same level of the figure. This compilation is consistent with four ranks of dominance, plus seven species (in parentheses) which cannot yet be allocated definitively to any one rank. C. commutata is listed as a species, distinct from C. foetida, merely for convenience: Babcock (1947) classifies them as subspecies $C$. $f$. commutata and $C$. $f$. vulgaris. The crosses providing these data are cited by Navashin (1934), except for setosa $\times$ nicaeensis (Babcock and Emsweller, 1936), neglecta $\times$ fuliginosa (Tobgy, 1943), four crosses involving kotschyana (Sherman, 1946), and three crosses reported here for the first time: capillaris $\times$ nicaeensis, capillaris $\times$ rubra, and aspera $\times$ fuliginosa.

\section{(iii) Meiosis in neglecta-capillaris hybrids}

The same general correspondence between secondary constrictions and nucleoli holds during pollen formation in the only hybrid, neglecta-capillaris, from which we have studied enough meiotic stages. Only one nucleolus is seen in cells of young anthers, where mitotic divisions reveal only one secondary constriction, on the capillaris D chromosome (plate I, fig. 1). Pollen mother-cells contain only one nucleolus, which is attached to the secondary constriction of the capillaris D chromosome at pachytene (plate I, fig. 2) and remains associated with that segment even after the constriction has disappeared during further shortening of the chromosomes (plate I, fig. 3). Meiosis becomes progressively more abnormal with succeeding 
phases. The chromosomes usually remain unpaired and closely invest the nucleolus at diplotene, reappearing as very condensed univalents at metaphase. Generally it seems that unpaired chromosomes migrate randomly to one of the poles in successful divisions (cf. Navashin, 1927; Babcock and Emsweller, 1936). Where chromosomes pair and form chiasmata, it is unlikely that crossing over would occur frequently between the centromere and neighbouring secondary constriction in a neglecta $\mathrm{D}$-capillaris $\mathrm{D}$ bivalent, so reductional division is still expected in this case. This is important because the few normal dyads that we have observed contain a nucleolus in each interkinetic or prophase II nucleus (plate I, fig. 6). Our observations indicate that one of these nucleoli can be ascribed to a re-activated neglecta $\mathrm{D}$ chromosome. It has often been reported, however, that univalents may divide at metaphase I, in which case each dyad could contain a capillaris D chromatid. This equational division is easily confused with a separation of chromatids during anaphase II which follows an abortive first division. Where we have suitable preparations and can distinguish the two situations, the latter seems more common. One example (plate I, fig. 5) will serve to show that synapsis, univalents and possibly equational division can occur in the same nucleus. Normal tetrads are seen quite frequently, and regularly contain one nucleolus in each nucleus (plate I, fig. 7). Two of these nucleoli must mark the presence of capillaris D chromatids, and consequently the other two nucleoli indicate the renewed activity of the neglecta $\mathrm{D}$ chromatids. We conclude that the neglecta $\mathrm{D}$ chromosome recovers its ability to form a nucleolus as soon as it has segregated from the marked capillaris D chromosome, probably at the first meiotic division and certainly at the second one. We can probably exclude any influence from the capillaris A or $\mathrm{G}$ chromosomes in this interaction, as random segregation at metaphase I should ensure that they co-exist with neglecta $\mathrm{D}$ chromatids in some of the tetrads that possess nucleoli.

Abnormal meiotic divisions were encountered much more frequently than normal ones in this hybrid. The following variants were particularly common, and contribute to our conclusions. Failure of anaphase I resulted in up to seven micronuclei, two of which usually contained small nucleoli. Failure of anaphase II resulted in dyads containing several micronuclei; one or two nucleoli were present in each dyad and two could co-exist in the same nucleus, presumably formed by sister chromatids. Unequal cell divisions resulted in from two to five microspores of variable size, some with micronuclei, and a total of up to four nucleoli. These abnormal divisions show that neglecta $\mathrm{D}$ chromosomes can resume their activity in forming nucleoli when isolated from capillaris chromosomes only by nuclear membranes and the intervening cytoplasm; isolation by a cell wall is not essential for this recovery. Crosby (1957) similarly found that specific weak SAT chromosomes of wheat could organise a nucleolus when isolated in a micronucleus. These abnormal variants of the second meiotic division show secondary constrictions on the neglecta D chromatids (plate I, fig. 4), for the first time in the hybrid and following both their segregation from capillaris chromosomes and the reappearance of a nucleolus associated with the neglecta $\mathrm{D}$ chromosome as noted above. The reappearance of the neglecta secondary constriction provides an even more immediate demonstration of its recovery than the observation of Navashin (1934) that it could be seen in the following generation in suitable back-crosses. 


\section{(iv) Ribosomal RNA}

Since the immediate product of the nucleolar organiser is a ribosomal RNA (rRNA) precursor molecule (see Birnstiel, 1967), the failure to produce a nucleolus might well be a reflection of a failure of $r$ RNA transcription. Our results thus suggest that a hybrid showing differential amphiplasty should contain rRNA transcribed only from the dominant organiser. If the rRNA of the parent species can be distinguished, the rRNA of the hybrid should resemble that of the parent which contributed the dominant organiser but differ from that of the other parent and from an intermediate situation. We have tested this hypothesis in terms of the base composition of rRNA, because that is technically easiest although not sufficiently precise to reveal differences of less than 1 per cent. for any one base. We isolated ribosomal pellets from leaves, extracted RNA from the pellets, purified nominal 25s and 16s rRNA (see Wallace, 1969), and subjected these preparations to acid

TABLE 2

Base composition of ribosomal RNA in 2 Crepis species and their hybrid. (Bases are given as percentages \pm standard error from $\mathrm{n}$ chromatographic separations.)

\begin{tabular}{|c|c|c|c|c|c|}
\hline 25s RNA & $n$ & $\mathrm{U}$ & C & A & G \\
\hline C. capillaris & 18 & $21 \cdot 0 \pm 0 \cdot 2$ & $21 \cdot 9 \pm 0.3$ & $25 \cdot 4 \pm 0.3$ & $31 \cdot 6 \pm 0 \cdot 4$ \\
\hline C. leontodontoides & 14 & $21 \cdot 3 \pm 0.3$ & $22 \cdot 8 \pm 0.3$ & $24.4 \pm 0.2$ & $31.4 \pm 0.2$ \\
\hline cap.-leont. hybrid & 10 & $20 \cdot 6 \pm 0.4$ & $22 \cdot 5 \pm 0 \cdot 2$ & $24.5 \pm 0.3$ & $32 \cdot 4 \pm 0 \cdot 3$ \\
\hline \multicolumn{6}{|l|}{ 16s RNA } \\
\hline C. capillaris & 11 & $20 \cdot 8 \pm 0 \cdot 6$ & $23 \cdot 0 \pm 0 \cdot 5$ & $25 \cdot 7 \pm 0.4$ & $30 \cdot 5 \pm 0.5$ \\
\hline C. leontodontoides & 8 & $20 \cdot 0 \pm 0.4$ & $21 \cdot 8 \pm 0.6$ & $26 \cdot 5 \pm 0 \cdot 3$ & $31 \cdot 6 \pm 0 \cdot 6$ \\
\hline cap.-leont. hybrid & 4 & $21 \cdot 7 \pm 0.5$ & $22.4+0.7$ & $25.3+0.7$ & $30 \cdot 8+0 \cdot 3$ \\
\hline
\end{tabular}

hydrolysis and paper chromatography. Determinations from 10 Crepis species showed no consistent differences in base composition (Langridge, Kling and Wallace, in preparation). Data obtained from C. capillaris, C. leontodontoides and their hybrid are shown in table 2. The hybrid rRNA shows a closer overall resemblance to the dominant parent, capillaris, than it does to leontodontoides, but cannot be distinguished from the latter as the range of twice the standard error about any one hybrid value overlaps with that for either parent species. The rRNAs of different species in the same genus are clearly very similar or even identical, just as they are functionally equivalent. Although we are unable to test the hypothesis in terms of rRNA composition, this information can be applied to that of the previous section. If our cytological evidence of inactivation of the nucleolar organiser is accepted as a repression of rRNA synthesis, then the specific organisers must differ in their repressibility but produce functionally equivalent rRNA. They therefore fit into the definition of iso-alleles. The cytological evidence is also consistent with the interpretation that the dominant organiser is the source of repression of its recessive iso-allele. In other words, it is conceivable that differential amphiplasty may be a case of allelic repression, analagous to recently discovered examples in other hybrids (Castro-Sierra and Ohno, 1968; Klebe, Chen and Ruddle, 1970).

\section{Discussion}

The basic result of this study has been to relate the formation of nucleoli to differential amphiplasty, in Crepis hybrids where the latter phenomenon 
was first discovered. As exemplified by the neglecta-capillaris hybrid, the neglecta $\mathrm{D}$ chromosome fails to organise a nucleolus and fails to show a secondary constriction only when capillaris chromosomes are present in the same nucleus. In other words, the capillaris chromosomes, probably the capillaris $\mathrm{D}$ chromosome alone, somehow inactivates the neglecta nucleolar organiser. The absence of a secondary constriction in this situation provides evidence that this segment of the chromosome contracts normally at prophase unless prevented by the mechanical interference of a nucleolus. This general conclusion has been anticipated to some extent by other reports of differential amphiplasty. Interspecific hybrids of Salix (Wilkinson, 1941, 1944) and Ribes (Keep, 1960, 1962) revealed a correlation between the number of secondary constrictions and the maximum number of nucleoli. Studies of trispecific hybrid Triticum vulgare further demonstrate that the dominant SAT chromosomes uniquely prevent the formation of both nucleoli and secondary constrictions by "latent organisers" on other chromosomes (Crosby, 1957; Longwell and Svihla, 1960). The concept of latent organisers is equivalent to that of differential amphiplasty. The restriction of this phenomenon to interspecific hybrids, if justified, suggests that is the consequence of an evolutionary divergence of either the nucleolar organiser or its regulatory system. A more detailed genetic analysis must probably await the discovery of differential amphiplasty in an organism with known linkage groups, although mammalian somatic cell hybrids could provide pertinent information (as inferred from Matsuya and Green, 1969). Even a tentative interpretation of the present results, however, requires a clarification of the nature of the nucleolar organiser, its part in the formation of the nucleolus and the regulatory systems involved in that process. To this end, we offer a reappraisal of McClintock's (1934) studies on maize, in relation to the recent discoveries of ribosome biosynthesis.

McClintock (1934) defined the nucleolar organiser on the basis of a reciprocal translocation between chromosomes 6 and 9 in maize. The break in chromosome 6 had occurred in a relatively large (pachytene) chromomere at the base of the secondary constriction. The new translocated chromosomes, $6^{9}$ with most of this chromomere and $9^{6}$ with a distal portion of the chromomere (and old secondary constriction and satellite), could both form nucleoli. Each formed a normal-sized nucleolus when isolated in microspores. When in the same nucleus, they seemed to compete as the smaller chromomere fragment on $9^{6}$ showed the greater functional capacity by forming the larger nucleolus and regularly expressing the secondary constriction. Presumably it was the observation that chromosome $6^{9}$ formed a nucleolus, although it lacked the original secondary constriction, which persuaded McClintock (and Birnstiel, 1967) that the constriction was no part of the nucleolar organiser. Yet chromosome $6^{9}$ does sometimes express a new secondary constriction, traversing the nucleolus and apparently composed of part of the former chromomere (McClintock, 1934, fig. 19). This observation demonstrates the same malleability of chromosome form encountered in differential amphiplasty, and at the same time invalidates McClintock's argument. The nucleolar organiser is a segment, not a point, on a chromosome (discussed below) and any part of it is liable to remain as a constriction if its prophase contraction is impeded by a persistent nucleolus. We can thus reconcile McClintock's observations with those of Heitz (1931), to assert that both the secondary constriction and its basal chromomere 
constitute the nucleolar organiser. It is pertinent that isolated nucleoli only contain a minor proportion of the genes coding for ribosomal RNA (Chipchase and Birnstiel, 1963; McConkey and Hopkins, 1964). It is only the constriction, however, which is seen to traverse or circumvent the nucleolus at meiotic prophase (plate I, fig. 2), that is appropriately situated to specify nucleolar material. The rate of nucleolar RNA synthesis decreases during meiotic prophase in maize (Das, 1965). On that basis, we envisage a continued transcription of ribosomal genes on the constriction during pachytene, while the chromomere grows by acquisition of inactivated ribosomal genes. The competitive capacity of organiser fragments found by McClintock is no longer paradoxical in these new terms. Chromosome $9^{6}$ which forms the larger nucleolus also carries the original secondary constriction and may thus represent the major fragment of the nucleolar organiser.

McClintock's (1934) other main conclusion was a cautious acceptance of the older matrix hypothesis, that the nucleolar organisers collected material from telophase chromosomes. This appeared to be the most likely explanation of the numerous nucleolus-like droplets both in microspores which lacked nucleolar organisers and in microspores which contained organisers but lacked a segment of chromosome 9. Such droplets have commonly been regarded as uncollected nucleolar material (e.g. blobs of Wallace, 1962). This has since been corrected by Swift and Stevens (1966), as the droplets of maize microspores lack the granular component (probably ribosomal precursors and subunits) of true nucleoli, and are present but seldom noticed in normal microspores (plate I, fig. 6). The same distinction can be made between the nucleoli of Xenopus and the blobs of anucleolate mutants (Jones, 1965).

More recent information on the compositon and formation of the nucleolus is admirably reviewed by Birnstiel (1967). It is generally accepted that the nucleolar organiser in eukaryotes is composed of over one hundred repeated cistrons which specify a ribosomal RNA precursor molecule, and constitues 0.1 per cent. to 1 per cent. of the genome (Ritossa and Spiegelman, 1965; Wallace and Birnstiel, 1966; Matsuda and Siegel, 1967). The repitition explains why organiser fragments can transcribe rRNA, and the amount of DNA is surely sufficient to occupy both the constriction and an adjacent chromomere (cf. Rafferty and Sherwin, 1969). The evidence for rRNA synthesis within the nucleolus is incompatible with any variant of the matrix hypothesis. Other nucleolar constituents, however, are presumably collected to the nucleolar organiser. $5 \mathrm{~s}$ rRNA is specified elsewhere on the genome of Xenopus (Brown and Weber, 1968) but becomes part of the larger ribosomal subunit. Both 5s rRNA and ribosomal proteins exist in pools before being incorporated into maturing ribosomes in the nucleolus of HeLa cells (Warner and Soeiro, 1967; Knight and Darnell, 1967). The term collection may be ambiguous in this context. This kinetic evidence suggests that ribosomal proteins are synthesised on cytoplasmic ribosomes and are genuinely collected onto nascent rRNA (see Maden, 1968). Birnstiel (1967) cites evidence that isolated nucleoli contain all the factors required for protein synthesis. It follows that if the genes specifying $5 \mathrm{~s} r \mathrm{rNA}$ and mRNA for ribosomal proteins are aggregated as nucleolus-associated chromatin, then ribosome production could be completely localised. There is enough uncertainty here to permit a version of the matrix hypothesis.

The production and collection of these nucleolar materials appears to be 


$$
\begin{aligned}
& \text { 39 (N) } \\
& \text { थै। } \\
& \text { tis: : : }
\end{aligned}
$$


All the microphotographs were taken of temporary squash preparations from neglectacapillaris anthers.

Fig. 1.-Mitotic metaphase. Only the capillaris D chromosome bears a secondary constriction (top).

Fig. 2.--Pachytene with the secondary constriction on the capillaris D univalent, and a nucleolar ghost below it.

Fig. 3.-Diplotene with the nucleolus attached to the capillaris D univalent.

Fig. 4.-Anaphase II following an abortive first division. Fourteen chromatids are present. Note secondary constrictions on capillaris D (left) and neglecta D (right) chromatids.

Frg. 5.-Metaphase I (above) and anaphase I (below). The anaphase figure shows a chiasma had occurred between the unequal A chromosomes on the left; two univalents (capillaris $\mathrm{C}$ and $\mathrm{D}$ ) are nearer the upper pole, the neglecta $\mathrm{D}$ univalent is nearer the lower poic; the two smallest chromosomes (neglecta $\mathrm{B}$ and $\mathrm{C}$ ) remain at the equator, perhaps about to divide equationally.

Fig. 6.-Dyad with a nucleolus in each interkinctic nucleus and several similarly staining "nucleolus-like" droplets.

Fig. 7.- Tetrad with a nucleolus in each microspore nucleus. 
regulated, according to the sporadic evidence available. The formation of $28 \mathrm{~s}$ and $18 \mathrm{~s}$ rRNA is co-ordinated genetically by the common precursor molecule, and the production of that is controlled cytoplasmically in Xenopus embryos (Gurdon and Brown, 1965). In the same material, the production or accumulation of $5 \mathrm{~s}$ rRNA and ribosomal proteins is co-ordinated with that of 28s and 18s rRNA (Brown and Weber, 1968; Hallberg and Brown, 1970). This leads to a possible interpretation of the absence of nucleoli in maize microspores which carry organisers but lack part of chromosome 9 . If this deletion includes the genes that specify $5 \mathrm{~s} r \mathrm{RNA}$ or ribosomal proteins, for instance, then the organiser may be inactivated or produce only unstable ribosome precursors.

Differential amphiplasty is further evidence for the regulation of nucleolar formation. The most direct interpretation here, consistent with the preceding discussion, is that the transcription of rRNA precursor molecules is repressed, possibly by a normal repressor of the dominant iso-allele which is confined to the same nucleus. According to this interpretation, the regulation of ribosomal cistrons is a typical case of a repressible system which operates under licence from other nuclear and cytoplasmic factors. The knowledge that ribosomal cistrons alternate with a non-transcribed spacer in the repeat units of the nucleolar organiser (Birnstiel et al., 1968; Dawid, Brown and Reeder, 1970), that organiser fragments can be transcribed independently, and the present argument for a regulatory system that represses transcription of rRNA, all point to one generalisation; each repeat unit may be functionally independent of the others, a ribosomal operon. This would add a variant to the regulatory systems envisaged by Birnstiel $(1967$, p. 48), for a quantitative control of ribosome production, which could be achieved with a constant rate of transcription by directly regulating the proportion of ribosomal operons which are transcribed.

\section{SUMmary}

1. A genetic control of the formation of nucleoli is demonstrated by relating nucleoli to the condition of differential amphiplasty in Crepis hybrids.

2. Since the nucleolar organisers of different Crepis species appear to be functionally very similar or even identical, differential amphiplasty is considered to be a case of allelic repression among the four detected iso-alleles of the organiser.

3. A rehearsal of pertinent information leads to the tentative conclusion that the nucleolar organiser consists of repeated ribosomal operons and occupies both the secondary constriction and an adjacent chromomere of SAT-chromosomes.

\section{REFERENGES}

вавсOCK, Е. в. 1947. The Genus Crepis. U. Calif. Pub. Bot., vols 21 \& 22, 1030 pp.

BABCOCK, E. B., AND EMSWELleR, s. L. 1936. Meiosis in certain interspecific hybrids in Crepis and its bearing on taxonomic relationship. U. Calif. Pub. Ag. Sci., 6, 325-368.

birnstiel, m. L. 1967. The nucleolus in cell metabolism. Ann. Rev. Plant Physiol., 18, 25-58. BIRNSTIEL, M., SPEIRS, J., PURDOM, I., JONES, K., AND LOENING, U. E. 1968 . Properties and composition of the isolated ribosomal DNA satellite of Xenopus laevis. Nature, 219 , 454-463. 
BROWN, D. D., AND WEBER, C. S. 1968. Gene linkage by RNA-DNA hybridization. I and II. 7. molec. Biol., 34, 661-697.

CASTRO-SIERRA, E., AND OHNO, s. 1968. Allelic inhibition at the autosomally inherited gene locus for liver alcohol dehydrogenase. Biochem. Genet., 1, 323-335.

Chipghase, M. I. H., AND Birnstiel, M. L. 1963. On the nature of nucleolar RNA. Proc. Nat. Acad. Sci. U.S., 50, 1101-1107.

collins, J. L. 1922. Culture of Crepis for genetic investigations. 7. Hered., 13, 329-336.

Crosby, A. R. 1957. Nucleolar activity of lagging chromosomes in wheat. Am. F. Bot., 44, 813-822.

DAS, N. K. 1965. Inactivation of the nucleolar apparatus during meiotic prophase in corn anthers. Exp. Cell Res., 40, 360-364.

DAWID, I. B., BROWN, D. D., AND REEDER, R. H. 1970. Composition and structure of chromosomal and amplified ribosomal DNAs of Xenopus laevis. 7. molec. Biol., 51, 341-360.

GURDON, J. B., AND BROWN, D. D. 1965. Cytoplasmic regulation of RNA synthesis and nucleolus formation in developing embryos of Xenopus laevis. 7. molec. Biol, , 12, 27-35.

HALLBERG, R. L., AND BROWN, D. D. 1969. Co-ordinated synthesis of some ribosomal proteins and ribosomal RNA in embryos of Xenopus laevis. 7. molec. Biol., 46, 393-411.

heITZ, E. 1931. Die Ursache der gesetzmässigen Zahl, Lage, Form und Grösse pflanzlicher Nukleolen. Planta (Berl.), 12, 775-844.

HUGHES, M. B., AND BABCOCK, E. B. 1950. Self-incompatibility in Crepis foetida (L.) subsp. rhoeadifolia (Bieb.) Schiz. \& Keller. Genetics, 35, 570-588.

JONES, K. w. 1965. The role of the nucleolus in the formation of ribosomes. F. Ultrastruct. Res., 13, 257-262.

KEEP, E. 1960. Amphiplasty in Ribes. Nature, 188, 339.

KEEP, E. 1962. Satellite and nucleolar number in hybrids between Ribes nigrum and $R$. grossularia and in their backcrosses. Can. F. Genet. Cytol., 4, 206-218.

KLEBE, R. J., CHEN, T., AND RUDDLE, F. H. 1970. Mapping of a human genetic regulator element by somatic cell genetic analysis. Proc. Nat. Acad. Sci. U.S., 66, 1220-1227.

KNIGHT, E., AND DARNell, J. E. 1967. Distribution of 5s RNA in HeLa cells. F. molec. Biol., $28,491-502$.

LANGridge, W. H. R., O'Malley, T. A., and wallace, H. 1970. Neutral amphiplasty and regulation of the cell cycle. Proc. Nat. Acad. Sci. U.S., 67, 1894-1900.

LONGWELL, A. C., AND SVIHLA, G. 1960. Specific chromosomal control of the nucleolus and of the cytoplasm in wheat. Exp. Cell Res., 20, 294-312.

MAdEN, в. Е. н. 1968. Ribosome formation in animal cells. Nature, 219, 685-689.

MATSUDA, K., AND SIEGEL, A. 1967. Hybridization of plant ribosomal RNA to DNA: the isolation of a DNA component rich in ribosomal cistrons. Proc. Nat. Acad. Sci. U.S., 58, 673-680.

MATSUYA, Y., AND GREEN, H. 1969. Somatic cell hybrid between the established human line D98 (presumptive HeLa) and 3T3. Science, 163, 697-698.

MCCLINTOCK, B. 1934. The relationship of a particular chromosomal element to the development of the nucleoli in Zea Mays. Zeit. Zellforsch. mik. Anat., 21, 294-328.

MCCONKEY, E. H., AND HOPKINS, J. W. 1964. The relationship of the nucleolus to the synthesis of ribosomal RNA in HeLa cells. Proc. Nat. Acad. Sci. U.S., 51, 1197-1204.

navashin (NAWAschin), M. 1925. Morphologische Kernstudien der Crepis-Arten in Bezug auf die Artbildung. Zeit. Zellforsch. mik. Anat., 2, 98-111.

navashin, M. 1927. Uber die Veränderung von Zahl und Form der Chromosomen infolge der Hybridisation. Zeit. Zellforsch. mik. Anat., 6, 195-233.

NAVASHin, M. 1934. Chromosome alterations caused by hybridization and their bearing upon certain general genetic problems. Cytologia, 5, 169-203.

RAFFERTY, K. A., AND SHERWIN, R. W. 1969. The length of secondary chromosomal constrictions in normal individuals and in a nucleolar mutant of Xenopus laevis. Cytogenetics, $8,427-438$.

richardson, M. M. 1935. Meiosis in Crepis. I. Pachytene association and chiasma behaviour in Crepis capillaris (L.) Wallr. and C. tectorum. L. F. Genet., 31, 101-117.

RITOSSA, F. M., AND SPIEGELMAN, s. 1965. Localization of DNA complementary to ribosomal RNA in the nucleolus organizer region of Drosophila melanogaster. Proc. Nat. Acad. Sci. U.S., 53, 737-745.

SHERMAN, M. 1946. Karyotype evolution: a cytogenetic study of seven species and six intraspecific hybrids of Crepis. U. Calif. Pub. Bot., 18, 369-408.

swanson, C. P., Merz, T., AND young, w. J. 1967. Cytogenetics. Prentice-Hall, New Jersey. 
SWIFT, H., AND STEVENS, B. J. 1966. Nucleolar-chromosomal interaction in microspores of maize. Nat. Cancer. Inst. Mono., 23, 145-166.

товGY, н. A. 1943. A cytological study of Crepis fuliginosa, C. neglecta and their $\mathrm{F}_{\mathbf{1}}$ hybrid, and its bearing on the mechanism of phylogenetic reduction in chromosome number. 7. Genet., 45, 67-111.

Wallace, H. 1962. Cytological and biochemical studies of anucleolate Xenopus larvae. Quart. F. micr. Sci., 103, 25-35.

WALLACE, H. 1963. Nucleolar growth and fusion during cellular differentiation. F. Morph., $112,261-278$.

WALLACE, H. 1969. Preparation of polyallomer centrifuge tubes for density gradients. Anal. Biochem., 32, 334-339.

WALLACE, H., AND BIRNSTIEL, M. L. 1966. Ribosomal cistrons and the nucleolar organizer. Biochim. Biophys. Acta, 114, 296-310.

warner, J. R., AND soeiro, r. 1967. Nascent ribosomes from HeLa cells. Proc. Nat. Acad. Sci. U.S., 58. 1984-1990.

wilkinson, J. 1941. The cytology of the cricket bat willow (Salix alba var. caerula). Ann. Bot., 5, 149-165.

wilkinson, J. 1944. The cytology of Salix in relation to its taxonomy. Ann. Bot., 8, 269-289. 